\title{
EL CAMPO ESCOLAR BAJO EL PERONISMO 1946-1955
}

\author{
Flavia Fiorucci ${ }^{1}$ \\ Universidad Nacional de Quilmes - Argentina \\ ffiorucc@yahoo.com
}

Recepción: 27/01/2012

Evaluación: 29/02/2012

Aceptación: 15/05/2012

Artículo de Reflexión

doi: 10,9757

\section{RESUMEN}

El trabajo estudia el impacto de la emergencia del régimen peronista en la vida escolar. Muestra que la escuela fue objeto de reformas y transformaciones importantes en esos años cuya implementación estuvo limitada por un contexto sumamente conflictivo. El artículo argumenta que la comunidad escolar reaccionó de formas muy variadas al nuevo movimiento político. El uso político que Perón hizo de la educación también estuvo condicionado por

\section{EDUCATIONAL FIELD UNDER PERONISM 1946-1955}

\section{ABSTRACT}

This paperwork studies the emergency impact during Peron's regime in education life. It shows that schools were object of changes and transformations in those years in which executing them was limitated by an extremely conflictive environment. This article proves that education community reacted in several ways to this new political movement. Peron made political uses from education fact that also made education very conditionated by the confict. Education place and schools were the melting pot in which Aregentinean society was aware of the whole conflict.

Palabras Claves: Journal of Latin American Education History, teachers, school, peronism, propaganda, vs. peronism, educational politics. esa conflictividad. Esto sucedió así porque establecimientos educativos fueron escenario del conflicto que agitaba a la sociedad argentina en su conjunto.

Palabras Claves: Revista Historia de la Educación Latinoamericana, maestros, escuela, peronismo, propaganda, anti peronismo, politica educativa.

\section{O CAMPO ESCOLAR SOB O PERONISMO 1946-1955}

\section{RESUMO}

O trabalho estuda o impacto da emergência do regime peronista na vida escolar. Mostra que a escola foi objeto de reformas e transformações importantes nesses anos cuja implementação esteve limitada por um contexto sumamente conflitivo. $\mathrm{O}$ artigo argumenta que a comunidade escolar reagiu de formas muito variadas ao novo movimento político. $\mathrm{O}$ uso político que Perón fez da educação também esteve condicionado por essa animosidade. Isto aconteceu assim porque estabelecimentos educativos foram cenário do conflito que agitava a sociedade argentina em seu conjunto.

Palavras - chave: Revista História da Educação Latino-americana, professores, escola, peronismo, propaganda, antiperonismo, política educativa.

\footnotetext{
Doctora en Historia por la Universidad de Londres. Es investigadora del Conicet. Forma parte del Grupo de Historia Intelectual de la Universidad Nacional de Quilmes. Ha publicado en medios argentinos y del exterior. Su área de investigación es la Historia Intelectual Argentina. Se encuentra en prensa un libro de su autoría: Intelectuales, Estado y Peronismo.
} 


\section{INTRODUCCIÓN}

Es sabido que el primer peronismo (1946-1955) utilizó a la escuela con fines políticos al hacerla responsable de una campaña para lograr consenso. Primero expandió su radio de acción en forma notable es decir democratizó el acceso, centralizó su administración, y luego introdujo innovaciones en el contenido de la enseñanza que remitían en forma positiva al régimen ${ }^{2}$. En paralelo a estas transformaciones la literatura señala que el gremio docente se posicionó en su mayoría en contra del peronismo y que el gobierno ejerció diversas formas de hostigamiento a los maestros desafectos ${ }^{3}$. La bibliografía describe como característico de la época sumarios, suspensiones y traslados, además de notas en la prensa con reclamos del magisterio de contenidos ideológicos y gremiales. Esto indicaría una situación inestable y contradictoria: un gobierno que interpela a un sector opositor -el de los docentes- como una suerte de difusor, de intermediario político. Este contexto ambiguo e incierto nos obliga a preguntarnos por la cotidianeidad de la escuela en esos años de la que sabemos muy poco. ¿Cómo vivió la comunidad escolar la emergencia del peronismo y la intromisión tan directa de la política en sus quehaceres y dinámicas diarios cuando quienes debían sostener la campaña a favor del peronismo estaban del lado opositor? ¿Es realmente una descripción apropiada la de catalogar al magisterio como parte de la oposición? ¿Cómo se manifestó en la vida escolar las transformaciones que la sociedad argentina vivía en ese momento?.

Este trabajo intenta echar luz sobre esos interrogantes. Para responder a esas cuestiones el trabajo se vale de diversas fuentes, en particular de una muestra aleatoria de sumarios realizados en esos años a los maestros de las escuelas que dependían del Consejo Nacional de Educación. El artículo busca

2 Estas reformas han sido estudiadas en forma minuciosa por la historiografía. Ver: Mariano Plotkin, Mañana es San Perón (Buenos Aires: Editorial Ariel, 1993); María Rein y Raanan Rein "Populismo y educación: el caso peronista", Ciencias de la Educación, V: No. 8 (1996): 50-57; Juan Carlos Tedesco "La educación argentina entre 1930 y 1955", en: Primera historia integral, (Buenos Aires: Centro Editor de América Latina , 1980); Silvina Gvirtz, "La politización de los contenidos escolares y la respuesta de los docentes primarios 1949-1955", en: Elprimer peronismo, eds. Raanan Rein y Sitman Rosalie (Buenos Aires: Lumiere, 2005), 37 -56.

3 Puiggrós y Bernetti sostienen que "hasta fines de los cuarenta grandes sectores del magisterio se mantuvieron en una posición ambigua, de expectativa y disconformidad ante la nueva forma que toma el estado". Ver: Adriana Puiggrós y Jorge Luis Bernetti "Los discursos de los docentes y la organización del campo profesional", en Peronismo: cultura política y educación (1945-1955), eds. Adriana Puiggrós (Buenos Aires: Editorial Galerna, 1993), 197. Ezequiel Adamovsky también señala que los docentes fueron más bien "reactivos" al peronismo y que las relaciones se volvieron más "tormentosas" luego de la segunda presidencia; aunque unas páginas después muestra cierta diversidad de posicionamientos del gremio docente frente al peronismo, al enumerar - en una nota al pie en la página 290- las agremiaciones dentro del sector docente que sí apoyaron a Perón. Ver: Ezequiel Adamovsky, Historia de la clase media argentina (Buenos Aires: Editorial Planeta, 2009), 259, 290 y 302. 
despegarse tanto de interpretaciones binarias -que colocan a la escuela o a alguno de sus integrantes, de un lado o del otro del espectro político- como de concepciones que se basan sólo en las políticas educativas. El artículo propone en su lugar observar cómo fueron afectadas las dinámicas de la vida escolar por la llegada del peronismo. En la primera sección se describen las reformas que el peronismo introdujo en el campo educativo. En la siguiente se analizan los sumarios y se discute su significado ${ }^{4}$. El tercer apartado se refiere al período posterior a 1952, cuando se inició la campaña de difusión del peronismo a través de la escuela. El artículo muestra cómo la escuela se convirtió en el escenario de los conflictos en que estaba sumida la sociedad argentina y cómo las reformas que el peronismo introdujo en el área educativa dieron lugar a procesos diversos que no siempre iban en consonancia con las intenciones estatales.

\section{El campo educativo y el peronismo}

La llegada del peronismo al gobierno en 1946 implicó cambios concretos en la dinámica del régimen educativo estatal porque supuso la reforma de organismos y leyes de larga data y, un incremento significativo en el número de alumnos y escuelas. Entre las modificaciones más reveladoras es preciso mencionar la creación de la Secretaria de Educación en 1948, la cual, en 1949 -con la sanción de la Ley Orgánica de Ministerios- se transformó en el Ministerio de Educación. Esa reforma implicaba la conversión del Consejo Nacional de Educación (CNE) en Dirección General de Enseñanza Primaria. Desde su organización en 1884, el Consejo Nacional de Educación funcionaba con relativa discrecionalidad: contaba con su propio presupuesto; tenía jurisdicción en el gobierno de las escuelas de la Capital Federal y los Territorios Nacionales, además de estar a cargo de la administración de los fondos asignados a las provincias para el fomento de la Instrucción Primaria ${ }^{5}$. Concretamente, la aparición de la Dirección de Enseñanza Primaria significaba la supresión de la autonomía funcional y financiera del Consejo que quedaba sujeto a la autoridad del ministro. La reforma de la burocracia educativa se justificaba en la propaganda gubernamental, en la necesidad de superar "el

$4 \quad$ Los sumarios dan cuenta de diversas cuestiones al mismo tiempo, y es posible analizarlos en función de múltiples interrogantes. Entre otras cosas, éstos muestran formas, mecanismos e instancias de interacción entre el Estado y la sociedad civil; recortan cartografías del poder en el mundo local y dejan entrever el lugar de la escuela y el docente en la sociedad de entonces. He analizado estos sumarios en forma minuciosa en otro trabajo; me interesa aquí recortar el significado de estos sumarios en relación con los dos interrogantes arriba mencionados. Ver: Flavia Fiorucci " $\mathrm{La}$ denuncia bajo el peronismo: el caso del campo escolar", (Buenos Aires: Mimeo, 2010).

5 Sobre el funcionamiento del Consejo Nacional de Educación se puede ver: República Argentina, Consejo Nacional de Educación Cincuentenario de la ley 1420 Tomo II, (Buenos Aires: Consejo Nacional de Educación, 1934). 
injustificado divorcio y la anarquía existentes entre las ramas de la enseñanza" y se asentaba en todo un nuevo ordenamiento estatal que tendía a reforzar la centralización de las políticas públicas ${ }^{6}$.

La expansión del sistema educativo durante el período del denominado primer peronismo fue notable. Si bien el estado argentino pretendía, desde la sanción de la ley 1420 en 1884, facilitar el acceso a la educación a todo el cuerpo social, las estadísticas mostraban un porcentaje de analfabetismo que todavía llegaba en 1943 al 15\% de la población. La cifra -aunque menor en el contexto de la época- escondía una situación de mayor precariedad. La deserción escolar era muy alta. Según los datos del censo de 1947, sobre cada mil personas de la población mayor de 15 años que había cursado únicamente estudios primarios, sólo 226 habían completado ese ciclo ${ }^{7}$. Para contrarrestar esa situación y, en consonancia con un gobierno que hacía de la democratización social un objetivo cardinal, en la primera presidencia de Perón -período en donde se concentró la obra pública del peronismo- se inauguraron según la estadística oficial 1069 escuelas; 1064 secciones de jardines de infantes; 6071 nuevas secciones de grado $^{8}$. También se fundó la escuela domiciliaria y la escuela de policlínicos para los niños imposibilitados por razones físicas de concurrir a los establecimientos escolares ${ }^{9}$. Se amplió además la enseñanza brindada por las escuelas nacionales que funcionaban en provincias, y que sólo cubrían el ciclo hasta cuarto grado de modo que cumplieran con todo el ciclo considerado obligatorio, es decir hasta el sexto grado.

A la par de las innovaciones de carácter más material el gobierno de Perón gestó transformaciones que tenían que ver con el sistema de valores que regían la educación estatal. Éstas se fueron generando en forma paulatina. El proceso comenzó con la institucionalización de un cambio que había sido introducido por el gobierno militar de junio de 1943. En 1947 el peronismo convirtió en ley el decreto militar de 1943 que había instaurado la enseñanza religiosa en las escuelas públicas, medida que como se sabe, alteraba uno

$6 \quad$ Ministerio de Educación de la Nación Labor desarrollada durante la primera presidencia del general Juan Perón, (Buenos Aires: 1952), Sobre los cambios en la gestión de la política pública y la burocracia estatal durante el peronismo, ver: Patricia M. Berrotarán, Del plan a la planificación. El estado durante la época peronista, (Buenos Aires: Imago Mundi, 2003), 87.

Héctor P. Agosti “El desarrollo cultural-escolar", en Nación y cultura, (Buenos Aires, serie Sociedad y Cultura: Centro Editor de América Latina, 1982), 85.

8 Sobre la promesa de democratización del bienestar ver: Elisa Pastoriza y Juan Carlos Torre "La democratización del bienestar en los años peronistas", en Los años peronistas, Tomo VIII, Nueva historia argentina eds. Juan Carlos Torre, (Buenos Aires: Editorial Sudamericana, 2002), 257-312.

9 Para las mejoras en la enseñanza primaria ver: Ministerio de Educación de la Nación Labor desarrollada durante la primera presidencia del general Juan Perón (Buenos Aires: 1952), 7-8. 
de los principios fundamentales del sistema educativo nacional: la laicidad ${ }^{10}$. El siguiente período de cambios en el plano simbólico se dio luego de la promulgación del Segundo Plan Quinquenal en 1952. El Plan, que declaraba la doctrina peronista como Doctrina Nacional, estipulaba la voluntad expresa de modificar los programas y en especial textos escolares para incluir en ellos los postulados del nuevo ideario político ${ }^{11}$. Es decir que a partir de 1952 la escuela fue concebida y, brevemente después, utilizada por el poder político como un instrumento para la difusión del ideario partidario peronista. En su conjunto, las innovaciones introducidas -tanto las que se referían a la gestión y a la ampliación del ámbito de acción de la escuela, como las que involucraban al ideario educativo- implicaban que el nuevo movimiento político otorgaba un lugar fundamental a la escuela en su proyecto. Cabe preguntarse ¿cómo el campo escolar en su conjunto vivió la emergencia de esta nueva experiencia y los cambios que la misma introdujo?

La llegada de Perón al poder, produjo un reordenamiento (al menos en términos simbólicos) de categorías y divisiones sociales. El peronismo se nutrió en una importante proporción del apoyo de los sectores populares y a través de su retórica pública confirió a los grupos trabajadores un protagonismo en la vida social y política desconocido hasta entonces. Enalteció además sus modos de vida y reafirmó el status de los sectores considerados subalternos ${ }^{12}$. Términos considerados oprobiosos, que significaban la humillación de la clase obrera -el caso más conocido fue el de descamisado- cambiaron sustancialmente de valoración ${ }^{13}$. Esta subversión de las formas aceptadas de la jerarquía y autoridad social vino acompañada de una gran conflictividad que dividió a la sociedad en identidades y grupos irreconciliables: peronistas versus antiperonistas. Ese conflicto bipolar permeó todos los ámbitos de la vida pública. Los estereotipos al que apelaron en esos días los miembros

10 La introducción de la enseñanza del catolicismo sobrepasaba el tema escolar. Tenía que ver con el sistema de alianzas que Perón había tejido en su camino a la presidencia. Como se sabe, el decreto fue resistido y criticado por la oposición antiperonista, pero también provocó malestar en algunos sectores del peronismo. Veintiún diputados de la mayoría se negaron a concurrir a la sesión en la que estaba previsto sancionarse la ley de educación católica que ya contaba con la aprobación del Senado y siete laboristas se retiraron del recinto antes de votar. Ver: Roberto Di Stéfano, Ovejas negras, (Buenos Aires: Editorial Sudamericana), 340.

11 En 1948 se formó una Comisión Revisora de Programas que propuso nuevos programas. Estos fueron implementados a partir de 1949. Introducían algunos elementos novedosos, como la enseñanza del ahorro, y enfatizaban el contenido patriótico, pero no intentaban difundir mensajes netamente político-partidarios. Ver: Miguel Somoza, Educación y politica en Argentina (1946-1955), eds. Miño y Dávila (Madrid: 2006), 138-171.

12 El trabajo pionero para observar cómo el peronismo alteró jerarquías sociales sigue siendo el de Daniel James, que aún en la actualidad no ha perdido validez. Daniel James, Resistencia e integración, (Buenos Aires: Editorial Sudamericana, 1990), 47.

13 James, "Resistencia", 47. 
de los sectores medios y altos para referirse a los peronistas, como el de "cabecita negra", son reveladores de las ansiedades de esos sectores frente a un proceso que percibían como de "nivelamiento" social ${ }^{14}$. La escuela -aun si observando dinámicas institucionales singulares- no fue ajena a ese proceso. La emergencia del peronismo supuso desencuentros en la vida escolar no sólo porque el peronismo legisló sobre ésta, sino porque la sociedad en su totalidad estaba en ebullición. En la escuela la conflictividad se puede observar en la presencia de numerosos sumarios donde la cuestión del peronismo estuvo en el centro de la escena ${ }^{15}$.

\section{Los Sumarios del peronismo}

Los sumarios constituyeron y constituyen todavía hoy- el dispositivo con el que contaba la burocracia educativa para sancionar a los docentes que no cumplían con los roles que habían sido determinados para ellos. Había distintos mecanismos para iniciar un sumario. Éste podía originarse en una actuación de oficio y por prevención por parte de las autoridades, o por una denuncia ${ }^{16}$. Esta última, según establecía la normativa vigente, podía ser expuesta "por cualquier persona capaz, no imposibilitada por las inhabilidades absolutas" ante las direcciones de las escuelas, inspecciones seccionales de las provincias y territorios y sus dependencias pero solamente ordenaban la instrucción del sumario, el CNE o su presidente, los Consejos Escolares y las Inspecciones Generales de las Provincias y Territorios. Para el caso de los empleados del CNE y los maestros, la denuncia de "era obligatoria y se consideraba falta grave el silenciarla" ${ }^{17}$.

Cuando se observan los sumarios que corresponden al período del primer peronismo que se encuentran en el Archivo Intermedio, es posible identificar la recurrencia de situaciones en donde lo que se denuncia es el antiperonismo de

14 En un interesante trabajo, Natalia Milanesio sostiene que los estereotipos y las descripciones de los antiperonistas sobre los sectores que apoyaban a Perón eran respuestas a un proceso al que percibían como una amenaza a sus identidades de clase, estilos de vida y estatus social. Ver: Natalia Milanesio "Peronists and cabecitas", en The New Cultural History of Peronism, eds. Matthew Karush y Oscar Chamosa (Durham: University Press, 2010), 55.

15 He evitado aquí el uso de cifras y porcentajes porque la investigación consiste en una muestra aleatoria y porque las autoridades del Archivo desconocen si los sumarios guardados en el Archivo Intermedio constituyen la totalidad de los procesos realizados.

16 El reglamento del Consejo Nacional de Educación mencionaba, entre las causas que motivaban la apertura de un sumario: la conducta delictuosa, desarreglada o inmoral, la transgresión de las leyes y el reglamento; desobediencia voluntaria; la incapacidad para el mantenimiento del orden y la disciplina y el atraso en la ciencia y el arte profesional.

17 El reglamento del sumario puede verse en la publicación del CNE citada arriba. República Argentina, "Cincuentenario", 768. 
un miembro de la comunidad escolar ${ }^{18}$. Las acusaciones provienen de distintas fuentes: maestros; directores; funcionarios locales; vecinos y padres. Éstas apelaban a tramas diversas cuya gravedad variaba según el caso. El primero de los sumarios que inaugura la serie se inició en febrero de 1946, en plena campaña electoral. Este se activó cuando las autoridades del Partido Laborista en Salta enviaron un telegrama al CNE informando que el inspector José Arce arengaba al personal docente en contra de Perón y favor de la UCR ${ }^{19}$. Acusaciones de este tipo contra un empleado del CNE se repetirían en los años venideros. Son numerosos los procesos administrativos que comenzaron por la denuncia de militancia antiperonista de un maestro, inspector o director de una escuela. Un caso similar al de Arce lo constituye la denuncia proferida en julio de 1947 por el ex presidente del peronismo del circuito de Arroyito (Córdoba). Éste acusó al director de la escuela Nacional N 347 de la zona, de estar "empeñado en una campaña de desprestigio y saboteo de la obra de la Revolución Nacional", incitando a "colonos y obreros a no acatar las leyes y a no colaborar en ningún sentido con la obra de gobierno", diciendo que Perón sólo les daría "miseria y hambre"20.

Las imputaciones que motivaron la apertura de los sumarios también traían a colación cuestiones incluso más triviales. Tal es el caso de la denuncia iniciada por un maestro contra el director de su escuela porque al observar el bosquejo de su clase sobre el tema ferrocarriles, este último le recriminó que "ensalzara la figura de Perón quien estaba procediendo como un dictador en todos los órdenes de la vida"21. En circunstancias análogas, la maestra Mercedes Vigna de la escuela $\mathrm{N}^{\circ} 50$ de Comodoro Rivadavia envió una comunicación al CNE en octubre de 1946 denunciando a la directora del establecimiento en el que trabajaba porque ésta la exhortó a corregir un discurso en donde halagaba a Perón. Según Vigna, la directora la recriminó por "hacer política en la escuela", y le recordó que lo mismo estaba prohibido ${ }^{22}$.

Los sumarios más enmarañados eran aquellos que además de la cuestión política mezclaban imputaciones que tenían que ver con la moral y el honor. Sobresale entre ellos el sumario realizado a la directora de la escuela al aire

18 Es preciso aclarar que las autoridades del Archivo Intermedio de la Nación -depósito de los procesos- no saben si los documentos que guardan en su acervo representan la totalidad de los documentos producidos por el CNE en esos años. Es, por ejemplo, muy notorio que los sumarios del año 1953 sumen unas pocas decenas de carpetas, mientras que para el resto de los años hay varios metros lineales de expedientes.

19 Expediente 32.391. En todos los casos citados he modificado los nombres para preservar la privacidad de las personas involucradas.

20 Expediente 34266.

21 Expediente 23766.

22 Expediente 3728. 
libre Número 8 que en 1946, fue acusada por la visitadora de higiene de tener amores con otra docente ${ }^{23}$. Dado el tenor de la imputación inmediatamente se inició una investigación sumarial, se intervino el establecimiento y se separó a la directora de su puesto hasta tanto se pudieran esclarecer los cargos. Si bien en este caso la denuncia inicial no se refería al antiperonismo de una docente, el sumario no era ajeno al conflicto en el que estaba sumergida la sociedad argentina. En un largo informe el interventor señaló que en el establecimiento de la directora acusada se "hablaba sin reparo alguno en contra del General Perón, de su obra de gobierno, desconociendo la obligación primaria de todo docente que consiste en expresarse y opinar con mesura de las personas y las cosas". El único sector que no participaban del complot antiperonista era -de acuerdo al reporte enviado al Consejo- el de las mucamas, las cuales, por su identidad política peronista eran maltratadas. El interventor se presentaba como el enviado del gobierno que venía a implementar en esa escuela "las normas de humanidad, de bien social y de defensa al bumilde que constitu [ían] la base y el fundamento de la doctrina politica del Primer Mandatario Argentino". El informe remitía al universo discursivo del peronismo: frente a las mucamas descriptas como "humildes, solidarias y abnegadas, sumisas y respetuosas" se contraponía la figura de la directora antiperonista y amoral. En 1957, la maestra acusada de homosexual demandó la revisión de su expediente presentándose como una víctima de "una [persona] peligrosa secuaz de la dictadura y delatora oficial", que la había condenado por su prédica en contra del peronismo en la escuela.

Claramente, quienes formulan las acusaciones al CNE, lo hacen porque creen que el antiperonismo es considerado por las autoridades una falta que motivará una sanción. Esto no quiere decir que los denunciantes sean todos militantes peronistas que estén desinteresadamente alertando a los poderes públicos sobre sus enemigos. Por el contrario, como se deduce de varios sumarios, muchas denuncias responden a conflictos que desbordan la cuestión política. Un caso ilustrativo a este respecto es lo sucedido en 1948 con el director de la Escuela N 39 del Territorio de La Pampa ${ }^{24}$. Este último fue denunciado por el padre de un alumno por un variado número de contravenciones entre las que se mezclaban aspectos ideológicos y partidarios.

23 He analizado en forma detallada este sumario en Flavia Fiorucci (en prensa): "Los amores de la maestra: sexualidad, moralidad y clase durante el peronismo". La visitadora tenía la función "revisar la vista, el oído y la boca de los niños de primer grado inferior; aplicar la vacuna antidiftérica a los alumnos autorizados por los padres; y secundar al médico en los consultorios de distrito". Con el peronismo, este cuerpo, que dependía del Ministerio de Justicia e Instrucción Pública, se incorporó al Ministerio de Salud Pública. Ver: Stella Maris Cornelis "Control y generación de los cuerpos durante el peronismo: La educación física como transmisora de valores en el ámbito escolar (19461955). Revista Aljaba Vol. 9 (2009): 105-121. Disponible en (2005) <http://www.scielo.org.ar/ scielo.php?script $=$ sci_arttext\&pid $=\$ 166957042005000100006 \& \operatorname{lng}=\mathrm{es} \& \mathrm{nrm}=\mathrm{iso}>$ 
Se lo acusaba de "tener militancia socialista"; "calificar de talentoso al diputado nacional Sanmartino por su frase de aluvión zoológico"; ser lector de La Vanguardia, hostigar a la única maestra peronista de la escuela y ser además "un depravado, que había sido visto en centros del hampa en un pueblito de mil habitantes en donde -como lo aclaraba el escrito enviado al CNE- todo se sabía." En la investigación sumarial se desestimó la imputación porque se demostró que el firmante de la acusación era un vecino analfabeto.

$\mathrm{Su}$ autor fue otro maestro, cónyuge de la maestra supuestamente hostigada por el director. El cargo hecho por un grupo de padres contra la directora de una escuela rural de la provincia de Jujuy afirmando que sus hijos eran maltratados por peronistas, fue desestimado también por el inspector al descubrir que varias de las firmas eran apócrifas. Resentimientos de clase y altercados que involucran al cónyuge de la directora, subyacían a la denuncia. El texto de la imputación presentado por los progenitores al Consejo de Educación es transparente en relación a las motivaciones que subyacían a esta denuncia. En el escrito se afirmaba que el "señor esposo de la directora" se desempeñaba como contador en "una de las Compañías Inglesas más importantes del norte, donde en cualquier problema obrero defiende a su patronal aunque el obrero tuviera toda la razón ${ }^{25}$. Varios de los padres que firmaban la acusación eran empleados de esa compañía.

Como se deduce de estos dos últimos casos, los sumarios siguieron caminos impredecibles. Acusar a alguien de antiperonista no era garantía de una sanción. Si bien es cierto que la burocracia educativa reaccionó a las tramas más nimias e inverosímiles; ésta investigó, respetó los procedimientos institucionales y, evitó particularmente castigar a miembros de la comunidad escolar que gozaran de reputación en su medio como he mostrado en otro trabajo. Incluso varios denunciantes fueron sancionados por fabricar cargos o por comprometer la concordia en la comunidad. La directora que en Santiago del Estero acusó a una docente de su escuela de obviar invitar al vecindario a un homenaje a Eva Perón fue apercibida por el Consejo de proceder en forma injusta con su personal. No obstante, es innegable que algunos docentes fueron objetos de represalias por acusaciones que tenían que ver con su filiación política antiperonista. El vicedirector de la escuela rural de Concepción de la Sierra en Misiones procesado por comunista y radical, fue trasladado a otra escuela para evitar inconvenientes, incluso cuando el sumario no pudo determinar la veracidad de los cargos ${ }^{26}$.

Expediente 16.200 .

26 He analizado en forma más pormenorizada estos sumarios y, en especial, el significado de la práctica de la denuncia bajo el peronismo en Flavia Fiorucci "La denuncia bajo el peronismo. El caso del campo escolar", (mimeo 2009). 
¿Qué nos dicen los sumarios sobre la relación entre el peronismo y el campo educativo? Los sumarios dan cuenta de la heterogeneidad de posiciones dentro del magisterio frente al peronismo. Advierten que había sectores del magisterio que se oponían alperonismo, incluso aceptando que no todas las denuncias eran verdaderas. Al mismo tiempo recortan un sector del campo educativo que apoya al nuevo movimiento político, que además cree (ya sea por convicción u oportunismo) que la adopción de esa identidad los autoriza a desacreditar a los otros. Claramente, detrás cada una de las acusaciones contra los antiperonistas, subyace la imagen de un estado receptivo a estas tramas; de un régimen que fallará a favor de quienes lo defiendan y protejan. Además, como hemos visto, no todas las denuncias provienen de funcionarios públicos, lo que deja entrever una situación de efervescencia y conflicto que sobrepasa y desborda a la escuela. Estos conflictos reflejan las tensiones que inundan la sociabilidad más micro bajo el peronismo: la del barrio y del vecino. Es decir que desde los primeros días el peronismo motivó divisiones, quiebres y conflictos en la comunidad escolar y en sus alrededores. Esas divisiones no fueron sólo entre maestros entre sí sino también entre éstos y su directivos y entre el personal de la escuela y los vecinos. La descripción de la relación entre peronismo y campo educativo no puede por lo tanto reducirse ni a una recepción positiva o negativa. La escuela vivió con inflexiones propias el conflicto que envolvía a la sociedad en su conjunto.

\section{Los docentes y la peronización de los contenidos educativos}

Como ha sido mencionado por numerosos trabajos, el régimen peronista fue progresivamente ajustando los mecanismos de control y adoctrinamiento de la sociedad civil, sobre todo a partir de la segunda presidencia ${ }^{27}$. El gobierno asignó un papel muy importante a la escuela en esta etapa porque se intentó utilizarla como un mecanismo para generar mayor adhesión y consenso ${ }^{28}$. Los considerandos del Segundo Plan Quinquenal sobre el contenido de los libros escolares -que éstos se debían adaptar a la Doctrina Nacional- se tradujeron en la producción de nuevos manuales. Los textos elaborados luego de 1952 contenían referencias concretas a la obra oficial, a las figuras de Eva y Perón y remitían en tono positivo a las transformaciones sociales introducidas por

27 En el plano político, la presión sobre la oposición se materializó en una serie de transformaciones institucionales que comenzaron con la sanción de la Constitución en 1949, que introdujo la reelección del presidente; la reforma del estatuto de los partidos políticos en el mismo año y la ley electoral en 1951. Entre otras cosas, el nuevo estatuto prohibía la formación de coaliciones y la ley electoral introducía el mecanismo de la circunscripción uninominal que favorecía al peronismo. Ver: Marcela García Sebastiani Los antiperonistas en la Argentina peronista, radicales y socialistas en la politica argentina entre 1943 y 1951 (Buenos Aires: Prometeo Libros, 2005), 67.

28 Sobre este tema ver: Mariano Plotkin Mañana es San Perón. (Buenos Aires: Editorial Ariel, 1993), 45. 
el nuevo gobierno. Enfatizaban por ejemplo la presencia de los trabajadores que aparecían en oposición a la oligarquía. Este uso político-partidario de los contenidos educativos era inédito en la historia nacional. Aunque es sabido que la enseñanza en los tiempos previos a Perón no fue políticamente neutra -fue empleada para propagar ideales cívicos y patrióticos- hasta entonces nunca había sido utilizada como medio para la divulgación de proposiciones partidarias particulares.

Claramente, la operación (difundir al peronismo a través de la escuela) requería la colaboración de los docentes e implicaba por lo tanto, una particular visión de estos agentes estatales. Un escrito publicado por el Ministerio de Educación para explicar los objetivos en torno a la educación del Segundo Plan Quinquenal declaraba al respecto que si bien el cumplimiento de la doctrina nacional era "obligatorio para todos los argentinos", "era para los docentes sobre quienes pesaba esta obligación con mayor exigencia". Porque, como concluía el mismo folleto, eran ellos quienes estaban encargados de "la formación del pueblo"29.

Perón volvió en más de una ocasión sobre la necesidad de contar con la ayuda de los maestros para garantizar la propagación de sus ideales. En un contradictorio mensaje en la apertura del ciclo de 1953, afirmó que si bien no quería maestros que "hicieran política de partido en las escuelas", sí pretendía que "cada maestro argentino [sirviera] lealmente al pueblo y a la Patria, inculcando en las generaciones futuras ...la Doctrina Nacional'. No había dudas que el peronismo interpelaba al gremio docente como un aliado en la construcción de su hegemonía ${ }^{30}$. No es casual que en la etapa peronista -en especial luego de 1952- los docentes hayan sido beneficiarios de mejoras concretas que culminaron en la sanción por decreto en 1954 de un "Estatuto del Docento". Entre otras cosas el estatuto garantizaba mayor estabilidad para los maestros y un incremento muy significativo en sus salarios. Residía aquí la estrategia de cooptación de un gobierno que buscaba la adhesión de un sector de la sociedad que consideraba clave en la construcción de su proyecto político ${ }^{31}$. La justificación del decreto que estableció el estatuto es particularmente iluminadora del rol que el peronismo le adjudica al maestro. Si bien el estatuto se justificaba en la necesidad de "dar permanencia y fuerza legal" a los nuevos beneficios, éste era presentado como un premio e incentivo a funcionarios

29 Citado en Ministerio de Educación de la Nación La educación en el Segundo Plan Quinquenal, (Buenos Aires: Ministerio de Educación, 1953), 7, citado por Miguel Somoza, Educación y politica en Argentina (1946-1955), eds. Miño y Dávila, (Madrid, 2006): 127.

30 Decreto N 15.535 del 14 de septiembre de 1954.

31 Puiggrós, "Los discursos de los docentes", 213. 
que tenían en sus manos "la formación de las nuevas generaciones" y por lo tanto, la "continuidad histórica de la Nueva Argentina"32.

¿Cómo respondieron los docentes a esta demanda del régimen político? Sabemos, por lo visto hasta ahora, que la emergencia del peronismo había conmocionado el mundo escolar y que los maestros no habían reaccionado homogéneamente a los cambios políticos. También es conocido que la introducción de la enseñanza religiosa en las escuelas, había motivado reacciones negativas de sectores de la docencia. Un dato que no se puede desdeñar es que la tarea que le encomendaba el gobierno al maestro contradecía valores que habían sido fundamentales en su configuración social. Desde la organización del sistema educativo argentino el estado demandaba al docente la realización de tareas de contenido político e ideológico. Como se dijo arriba, fueron estos agentes los llamados a homogeneizar al cuerpo social en pleno proceso de construcción estatal. Concretamente, luego de la llegada masiva de inmigrantes a la Argentina, se requirió a los maestros difundir un discurso moral y patriótico que tenía como misión afirmar la nacionalidad; reestablecer un orden social que se creía amenazado y ayudar a formar al ciudadano ${ }^{33}$. Esto significaba que el estado depositaba en la figura del docente de escuela responsabilidades $y$ expectativas claves en la constitución de un orden político y social deseable, de las que se derivaban un sinnúmero de imperativos.

El maestro debía ser un ejemplo de "virtud pública y privada", "el vecino más apreciado por el conjunto de sus condiciones personales", tal como resumía un funcionario del Consejo ${ }^{34}$. Esto entrañaba que además de adquirir una determinada formación, la burocracia educativa solicitaba que el docente exhibiera un aspecto personal cuidado, gozara de una buena reputación intelectual y moral en su medio de actuación e hiciera gala de gestos y modos distinguidos ${ }^{35}$. Asimismo, como se suponía que éste debía constituirse en un agente de unión, se desaprobaba que

32 La convivencia de políticas conciliadoras junto con instancias de hostigamiento no es sorprendente. En un trabajo anterior he analizado las estrategias del peronismo para con los intelectuales, donde es claro que el régimen apeló al mismo tiempo a gestos conciliadores y de confrontación. Ver Flavia Fiorucci, Intelectuales, Estado y peronismo (en prensa).

33 Son varios los trabajos que se refieren al proyecto nacionalizador de la escuela. Para un comprensivo trabajo sobre la organización del sistema educativo que se refiere a este tema ver: Lucía Lionetti $L a$ misión politica de la escuela pública. Formar a los ciudadanos de la república (1870-1916), (Buenos Aires, 2007). Ver también: Andrea Alliaud, Los maestros y su historia. Los orígenes del magisterio argentino, (Buenos Aires: Editorial Granica, 2007). Al mismo tiempo, fueron convocados a promover el proyecto higienista, ya que la escuela fue imaginada como un centro difusor de nociones de higiene pública.

34 ([Indicaciones del Inspector General de Territorios]), transcripto en el Ministerio de Justicia e Instrucción Pública Digesto de Instrucción Primaria, (Buenos Aires, 1920), 442.

35 Ver al respecto Lucía Lionetti La misión política de la escuela pública. Formar a los ciudadanos de la república (1870-1916), (Buenos Aires: Miño y Dávila editores, 2007), 149-158. 
militara en política partidaria ${ }^{36}$. Como afirmaba el mismo funcionario citado arriba, el maestro "debía estar equidistante de todas las rivalidades, rencillas o pasiones que [pudiesen] dividir a los habitantes de una población" 37 . En las primeras décadas del siglo XX estas prescripciones se convirtieron progresivamente en regulaciones concretas. Una circular de noviembre de 1915 establecía que el maestro tenía prohibido hacer propaganda a favor o en contra de creencias religiosas o políticas. Retomando esa disposición, y en virtud de algunos problemas que se habían dado, el Digesto Escolar de 1937 aclaraba el alcance de esa norma. Según ese documento, "la afiliación a comités políticos, la propaganda pública a favor de determinados políticos, la concurrencia a manifestaciones y otros actos que demuestren una afiliación activa... así como la aceptación de candidaturas para desempeñar puestos electivos sin renuncia previa" le estaban vedados al magisterio ${ }^{38}$. Es decir que no sólo los contenidos impartidos por el sistema de educación pública debían ser políticamente neutros sino que la participación cívica de los docentes estaba limitada por ese mismo principio de imparcialidad. En consonancia con este requerimiento el estado también desalentaba fuertemente el gremialismo, al menos el que se relacionaba con la reivindicación de derechos laborales. Según una publicación de la década de 1930 para el Consejo Nacional de Educación era necesario evitar "la confusión de asimilar las sociedades de maestros a las obreras de resistencia", "para el maestro su interés y el de su empleador, el Estado, se identifican con el niño" 39 . No obstante, para la década de 1940 había numerosas entidades gremiales aunque no existía una organización a nivel nacional ${ }^{40}$.

Lo discutido arriba indica que la función que el peronismo depositó a partir de 1952 en los maestros, la difundir su ideario político, chocaba con un principio axial del orden educativo: el de la neutralidad político partidaria del docente. Incluso cuando la tarea era afín al accionar del magisterio -como mencionamos este sector había sido responsable de promover un imaginario cívico-patriótico particular. A esa cuestión se sumaba la situación de crisis en que el peronismo había sumido a la comunidad escolar y la existencia de sectores que desaprobaban el peronismo. La pregunta entonces es ¿cómo reaccionó este sector profesional frente a una demanda que contradecía uno de sus principios identitarios? ${ }^{21}$. Las fuentes permiten observar en el período posterior a 1953 la

36 Es necesario destacar que la exigencia de neutralidad política era una norma que no siempre se cumplía. Incluso, se sabe que los maestros fueron partícipes de las redes clientelares locales y de sus luchas, lo que claramente atentaba contra ese ideal de armonía que suponía neutralidad política. Lionetti, "La misión política de la escuela pública", 172.

37 Consejo Nacional, "Digesto de Instrucción”, 442.

38 Consejo Nacional de Educación "Digesto de Instrucción”, 59.

39 República Argentina, "Cincuentenario", 149.

40 Puiggrós, "Los discursos de los docentes", 197.

41 Este mismo dilema se presentó en 1943, cuando se introdujo la enseñanza religiosa. Como ya ha sido subrayado por la literatura el tema provocó crispaciones en el mundo docente. Un editorial de la revista La Obra de 1946 se quejaba del "embate totalitario y clerical" que se daba en las aulas. Citado por Puiggrós, "Los discursos de los docentes”, 201. 
persistencia de los conflictos que tienen que ver con el peronismo. En 1953 se abrió un sumario una maestra de la escuela N 593 de Santiago del Estero por no haber "acatado la orden interna de invitar al vecindario para una reunión en la que se tributaría un homenaje a la memoria de Eva Perón"42. Una situación similar se da con el maestro Horacio Bufa. Éste fue acusado en 1953 por el director de la escuela en la que ejercía (Escuela N 86 de Laguna Blanca, Chaco), por no respetar el luto ${ }^{43}$. Estos casos muestran que la escuela continuaba en 1953 siendo afectada por el conflicto peronismo-antiperonismo. Si bien en la muestra de expedientes que se analizaron no se registraron sumarios que tienen que ver específicamente con el uso político de la educación, con la implantación de los nuevos textos, la permanencia de este tipo de querellas hace difícil creer que la comunidad educativa acompañó uniformemente la convocatoria lanzada por el gobierno. Revelan además que el peronismo y su contraparte (el antiperonismo), seguían siendo motivos de disputa en la escuela.

Los libros producidos por orden del gobierno luego de 1952 dejan ver los mensajes que el régimen buscaba transmitir, de aquellas imágenes que quería que los alumnos asimilasen, pero su presencia no es indicadora dela posición de la comunidad de educadores, ni permite dilucidar cómo ésta tradujo y difundió esos mensajes. Se sabe que los manuales escolares son muy importantes en orientar el contenido de la educación pero no determinan las actividades en el aula. Los maestros normalmente reelaboran y negocian con los contenidos de los libros de texto y con aquellas ideas y opiniones que los alumnos ya traen consigo ${ }^{44}$. Es lícito pensar, aunque no hay investigaciones al respecto, que los maestros argentinos resignificaron el discurso patriótico que el estado había considerado tan importante difundir en las primeras décadas del siglo. Esto se puede deducir de algunas intervenciones en la revista $L a$ Obra -uno de los más importantes órganos de prensa de la docencia- cuyas páginas se refirieron en forma crítica al repertorio del nacionalismo oficial. La publicación se inclinaba por un nacionalismo más abocado al "conocimiento de la realidad del país que a sentimientos y pensamientos que supusieran una fuerte adhesión emocional

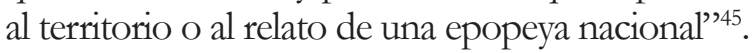

Para el caso del peronismo, Silvina Gvirtz, en un sugerente trabajo de análisis de los cuadernos escolares de la época peronista muestra que la institución escolar, a través de sus docentes y de ciertos mecanismos institucionales, neutralizaron el efectos de los contenidos peronistas. ${ }^{46}$ La utilización de

\footnotetext{
$42 \quad$ Expediente 58.464.

43 Expediente 70.122.

44 Sobre el tema de cómo los maestros difundieron el mensaje nacionalista ver: Matthias Vomhau "Unpacking the School: Textbooks, Teachers, and the Construction of Nationhood in Mexico, Argentina and Peru", Latin American Research Review, Vol. 44 No. 3, (2009):127-154.

45 En esta parte sigo el análisis de la revista La Obra de FINOCCHIO Silvia (2009): La escuela en la bistoria argentina, (Buenos Aires: Edhasa), p. 111.

46 Gvirtz, "La politización de los contenidos", 37-56.
} 
la escuela para difundir el ideario político requería de un gremio que apoyara sin fisuras al peronismo. Incluso si esta última situación se hubiera dado, tampoco estaba garantizada la efectividad de la campaña de propaganda. Investigaciones sobre la escuela han mostrado que los estudiantes se apropian selectivamente de los contenidos escolares ${ }^{47}$. Todo esto pone dudas sobre el alcance de la peronización de los contenidos educativos luego de 1952. Por el contrario el peronismo parece estar en el centro de un importante número de las disputas que se suscitaron en la escuela en esos años.

\section{CONCLUSIÓN}

Algunas de las lecturas de la relación entre educación y peronismo señalan que el uso político de la educación convirtió al sistema educativo oficial en un "engranaje de una maquinaria de propaganda" ${ }^{4}$. El material revisado aquí permite aseverar que si bien esa intención estuvo en el ánimo de los legisladores, el proyecto se insertó en un mundo convulsionado que no reaccionaba unánimemente frente al peronismo. La imagen que surge de las fuentes aquí citadas es la de una comunidad escolar fuertemente conmovida en todos sus niveles por el conflicto peronismo-antiperonismo. Los maestros no fueron ni un grupo homogéneo de leales agentes del régimen, ni de disciplinados miembros de la oposición.

La implantación de las políticas estatales en torno a la educación, en especial la campaña de difusión del peronismo, estuvo signada por esos límites. La escuela -observando inflexiones específicas- fue escenario y caja de resonancia de los conflictos que la emergencia del peronismo abrió en la sociedad argentina. Claramente, desde el gobierno sí se pensaba a los maestros como aliados en la tarea de lograr adhesiones. Para atraerlos el gobierno instituyó mejoras en las condiciones del ejercicio de la docencia. La convocatoria de Perón podía remitirse a experiencias nacionales previas pero también a ejemplos de otras latitudes como el llamado hecho por Lázaro Cárdenas en México para que los maestros participaran de una campaña de difusión de la educación socialista que tuvo resultados concretos porque -aún si conflictiva- contó con la colaboración de los maestros y la población ${ }^{49}$. La campaña del peronismo se insertó en cambio en un contexto signado por conflictos nuevos donde autoridades, maestros y vecinos redefinieron sus identidades políticas y sociales.

\footnotetext{
47 Un sugestivo análisis de cómo los alumnos se apropian selectivamente del currículum fue analizado por Ben Eklof Russian Peasant Schools- Officialdom, Village Culture and Popular Pedagogy, 1861 -1914 (Berkeley: University of California Press, 1986), 179-438.

48 Plotkin, "Mañana", 163-165.

49 Ver: Mary Kay Vaughan Cultural Politics in Revolution. Teachers, Peasants and Schools in Mexico, 19301940, (Arizona: University of Arizona Press, 1997).
} 


\section{FUENTES}

Consejo Nacional de Educación se puede ver: República Argentina, Consejo Nacional de Educación Cincuentenario de la ley 1420 Tomo II, Buenos Aires: Consejo Nacional de Educación, 1934.

Consejo Nacional, "Digesto de Instrucción”.

Consejo Nacional de Educación "Digesto de Instrucción".

Decreto N 15.535 del 14 de septiembre de 1954.

Expediente 3728, Expediente 16.200, Expediente 23766, Expediente 34266, Expediente 27.424, Expediente 58.464, Expediente 70.122.

([Indicaciones del Inspector General de Territorios]), transcripto en el Ministerio de Justicia e Instrucción Pública Digesto de Instrucción Primaria, Buenos Aires, 1920.

Ministerio de Educación de la Nación Labor desarrollada durante la primera presidencia del general Juan Perón, Buenos Aires: 1952.

\section{REFERENCIAS}

Agosti, Héctor P. "El desarrollo cultural-escolar", en Nación y cultura, Buenos Aires, serie Sociedad y Cultura: Centro Editor de América Latina, 1982.

Berrotarán, Patricia M. Del plan a la planificación. El estado durante la época peronista, Buenos Aires: Imago Mundi, 2003.

Di Stéfano Roberto. Ovejas negras. Buenos Aires: Editorial Sudamericana.

García Sebastiani Marcela. Los antiperonistas en la Argentina peronista, radicales y socialistas en la política argentina entre 1943 y 1951. Buenos Aires: Prometeo Libros, 2005.

Gvirtz Silvina, "La politización de los contenidos escolares y la respuesta de los docentes primarios 1949-1955", en: Elprimerperonismo, eds. Raanan Rein y Sitman Rosalie. Buenos Aires: Lumiere, 2005.

Kay Vaughan, Mary. Cultural Politics in Revolution. Teachers, Peasants and Schools in Mexico, 19301940, Arizona: University of Arizona Press, 1997.

Rein, María y Rein, Raanan. "Populismo y educación: el caso peronista", Ciencias de la Educación, V: No. 8 (1996): 50-57; Juan Carlos Tedesco “La educación argentina entre 1930 y 1955”, en: Primera historia integral. Buenos Aires: Centro Editor de América Latina, 1980.

Pastoriza Elisa y Torre Juan Carlos. "La democratización del bienestar en los años peronistas", en Los años peronistas, Tomo VIII, Nueva historia argentina eds. Juan Carlos Torre. Buenos Aires: Editorial Sudamericana, 2002.

Puiggrós, Adriana y Bernetti, Jorge Luis. "Los discursos de los docentes y la organización del campo profesional", en Peronismo: cultura politica y educación (1945-1955)

Plotkin, Mariano. Mañana es San Perón. Buenos Aires: Editorial Ariel, 1993.

Somoza, Miguel. Educación y politica en Argentina (1946-1955), eds. Miño y Dávila. Madrid: 2006.

Fiorucci, Flavia "El campo escolar bajo el peronismo (19461955)". Revista Historia de la Educación Latinoamericana Vol. 14 No. 18, (2012): pp. $139-154$. 